\title{
O ENSINO DE HISTÓRIA E A EDUCAÇÃO PARA RELAÇÕES ÉTNICO-RACIAIS: DIÁLOGOS COM OS ESTUDOS DESCOLONIAIS
}

\author{
Astrogildo Fernandes da Silva Júnior* \\ José Josberto Montenegro Sousa**
}

\begin{abstract}
Resumo
Este artigo, partindo do questionamento de como o ensino de história pode contribuir para a educação das relações étnico-raciais, tem como objetivo propor algumas reflexões sobre o lugar do ensino de história na educação das relações étnico-raciais a partir do diálogo com os estudos descoloniais. Para tanto, a metodologia adotada consistiu em pesquisas bibliográficas sobre o ensino de história, a educação para as relações étnico-raciais e os estudos descoloniais. Nele, apresentamos um estudo sobre o conceito de raça, registramos um olhar sobre o histórico de ações políticas internacionais e nacionais para o tratamento de questões relacionadas ao racismo, a fim de compreendermos a importância da educação para as relações étnico-raciais, e apresentamos uma proposta para efetivar uma história escolar a partir das contribuições dos estudos descoloniais. Concluímos, assim, que é na escola que recebemos informações que ajudarão a compor nossas formas de conhecer e lidar com as diferenças culturais e a construir a imagem que fazemos do outro; Dessa forma, construir relações étnico-raciais positivas, fundadas no respeito às diferenças e no reconhecimento da alteridade, deve ser pauta fundamental nas aulas de história.
\end{abstract}

Palavras-chave: Educação para as relações étnico-raciais. Ensino de história. Estudos descoloniais.

\footnotetext{
* Doutor em Educação pelo Programa de Pós Graduação em Educação (PPGED) da Universidade Federal de Uberlândia (UFU). Professor Adjunto do Curso de História da Faculdade de Ciências Integradas do Pontal (FACIP) da mesma instituição. E-mail: silvajunior_af@yahoo.com.br.

* Doutor em História pela Pontifícia Universidade Católica de São Paulo (PUC-SP). Professor Adjunto do Curso de História da Faculdade de Ciências Integradas do Pontal (FACIP) da Universidade Federal de Uberlândia (UFU).E-mail: josbertoms@yahoo.com.br.
} 


\section{Introdução}

Desde sua constituição como disciplina escolar, a história cumpriu, dentre outras prerrogativas, as expectativas de subsidiar processos de formação de identidades por meio do fornecimento de conteúdos ensináveis compatíveis a um determinado projeto de sociedade, orientado a partir de parâmetros disseminados pela modernidade ocidental europeia. O conhecimento do passado, em geral, está centrado na exaltação de heróis e de acontecimentos, os quais seriam os componentes de uma imagem de nação associada à de pátria, integradas como eixos indissolúveis que deveriam mobilizar determinados valores para a preservação da ordem organizada para assegurar a obediência à hierarquia, de modo a favorecer a assunção ao progresso a ser idealmente alcançado consoante a trajetória de países europeus.

Segundo Bittencourt (2004), no final do século XIX, com a proclamação da República, passou a ser função da escola denunciar os atrasos impostos pela monarquia, consequência das ideias positivistas. A educação escolar tinha, assim, o papel de regenerar os indivíduos e a própria nação, e, dessa forma, colocar o país na rota do progresso e da civilização. Para tanto, o ensino de história passou a ocupar, no currículo, um duplo papel, civilizatório e patriótico, pois serviria ao molde de um novo tipo de trabalhador, o cidadão patriótico. A história nacional passou, então, a se identificar com a história pátria - cuja finalidade era integrar o povo brasileiro à moderna civilização ocidental, reforçando a visão linear, determinista e eurocêntrica da história -, e seus conteúdos enfatizavam as tradições de um passado homogêneo de lutas e de feitos gloriosos de personagens identificados com ideais republicanos.

Em grande parte do século XX, apesar das sucessivas reformas dos governos republicanos, pouco foi feito para alterar a escola pública. $\mathrm{O}$ ensino de história, por exemplo, permaneceu como instrumento de desenvolvimento do patriotismo e da unidade étnica, administrativa, territorial e 
cultural da nação. No contexto da democratização do Brasil, após a Segunda Guerra Mundial, o ensino da disciplina tornouse significativo na formação de uma cidadania para a paz, uma vez que a proposta era a de um ensino revestido de um conteúdo mais humanístico e pacifista, voltado ao estudo dos processos de desenvolvimento econômico das sociedades, bem como dos avanços tecnológicos, científicos e culturais. Nos anos de 1950 e 1960, sob a inspiração do nacional-desenvolvimentismo, ele voltou-se para as temáticas econômicas; em 1964, com a implantação da ditadura militar no Brasil, desvalorizaram-se as áreas de humanas em favor de um ensino técnico, privilegiandose um conteúdo voltado para a formação moral e cívica e o ajustamento ideológico dos jovens aos objetivos e interesses do Estado, moldados pela doutrina de segurança nacional e de desenvolvimento econômico.

O caminho da democratização dos anos de 1980 foi caracterizado por uma série de transformações. Ao longo da história do ensino da disciplina em questão, houve mudanças e permanências em relação às suas finalidades, porém prevaleceu o objetivo de construir um determinado projeto de sociedade em consonância com os valores dominantes, de forma que se manteve uma versão excludente, opressora e silenciadora de diversos sujeitos que fizeram e fazem parte da constituição do país, prevalecendo o monopólio cultural detido pelo Norte, um ensino eurocêntrico e um olhar enviesado por estereótipos e visões pouco informadas sobre outras realidades, como, por exemplo, sobre os afro-descendentes e indígenas.

Como professores e formadores de professores de história, acreditamos que, ao se trabalhar com as relações étnicoraciais no ensino da disciplina é imprescindível abranger as diferentes experiências constituintes do patrimônio históricocultural das sociedades sem hierarquizá-las. É fundamental, portanto, estabelecer um diálogo entre diferentes, aberto para transformação de novas culturas e não para preservação de sua "essência". Insistimos que a compreensão do mundo excede os parâmetros estabelecidos pela presunção de superioridade disseminada pela modernidade ocidental. 
Para a escrita deste texto, partimos do seguinte questionamento: como o ensino de história pode contribuir para a educação das relações étnico-raciais? Assim, nosso objetivo consiste em propor algumas reflexões sobre o lugar do ensino de história na educação das relações étnico-raciais a partir do diálogo com os estudos descoloniais. Para tanto, organizamos o texto em três tópicos: no primeiro, empreendemos um estudo sobre o conceito de raça; no segundo, lançamos um olhar sobre o histórico de ações políticas internacionais e nacionais para o tratamento de questões relacionadas ao racismo para compreendermos a importância da educação para as relações étnico-raciais; e no terceiro, registramos nossa proposta de efetivar uma história escolar a partir das contribuições dos estudos descoloniais. Por fim, tecemos algumas considerações.

\section{O conceito de raça: um posicionamento político}

A noção de racialização está intimamente ligada, nos espaços coloniais, aos processos de classificação social, nos quais são incluídas diversas formas de pensamento étnico e nacionalista, permeados por construções raciais. O conceito de raça surgiu para hierarquizar os diferentes sujeitos, de forma a justificar a dominação e a exploração de alguns sobre os outros. Nesse sentido, compreendemos o conceito de raça relacionando diretamente com poder.

De acordo com McLaren (2000, p. 251), muitos filósofos contribuíram para efetivar o conceito de raça. Para Kant, por exemplo, os negros de África não tinham, por natureza, nenhum sentimento que os elevasse acima da insignificância, pois, segundo seu argumento, entre as centenas ou milhares de negros que eram transportados de suas regiões para outros lugares não houve nenhum que tenha apresentado algo de grandioso na arte ou na ciência. Segundo Hegel, historicamente, África não faria parte do mundo, pois ela não teria movimento ou desenvolvimento a apresentar, em contraposição ao mundo asiático e ao europeu, nos quais ocorriam os movimentos históricos.Benjamin Franklin, por 
sua vez, em discurso, questiona: "Por que elevar os filhos da África, plantando-os na América, onde temos uma oportunidade tão boa, excluindo os negros e mulatos, de elevar os brancos e vermelhos, tão adoráveis?” (MCLAREN, 2000, p. 251).) Thomas Jefferson concorda com isso ao se referir à presença de negros como "manchas". Além deles, em 1848, o senador norte-americano John Calhoun ressaltou: "Eu sei, senhores, que nunca sonhamos em incorporar em nossa União qualquer raça que não seja a caucasiana, a raça branca e livre [...]” (MCLAREN, 2000, p. 251).

Para McLaren (2000, p. 257), os discursos desses autores evidenciam aspectos da construção da condição branca, que se tornou uma medida para raças superiores e inferiores. Essa condição é fundamentalmente ocidental ou eurocêntrica. Segundo o autor, ser branco constitui práticas (euro-americanas e masculinas) não estigmatizadas que têm efeitos negativos para aqueles que não participam delas. É importante diferenciar brancura, que é relacionada à cor da pele, com branquitude ou condição branca, pois, segundo o autor, "Não se nasce branco, mas alguém se torna branco pelo contexto social no qual se encontra e, também, pelas escolhas que se faz" (MCLAREN, 2000, p. 269).

Tais questões nos colocam o desafio de desmantelar a condição branca. Consideramos que ao ensinar história, o professor pode contribuir cotidianamente para a superação do racismo ao provocar, nos estudantes, reflexões acerca do lugar do branco nas relações sociais, enfatizando que as pessoas brancas precisam superar os efeitos da transparência e da naturalização da raça para que possam reconhecer os vários aspectos raciais de sua identidade. Deve-se, portanto, mobilizá-los a embarcar em um processo diário de escolhas que se coloque contra a condição branca, pois é imperativo desnaturalizar essa condição.

Nesse processo, defendemos a manutenção do conceito de raça. Lembramos que este não consiste em uma essência, e sim em uma construção social, e reafirmamos que raça tem relação com o poder, uma vez que provoca efeitos no 
1 O texto integral está disponível em: <http://unesdoc.unesco. org/images/0013/001394 /139423por.pdf>. Acesso em: 26 out. 2016. imaginário social e na produção das identidades. Ela é, em nossa perspectiva, uma categoria fictícia que marca os sujeitos. Ao longo do século XIX, o conceito de raça fundamentou discursos científicos que classificavam as pessoas entre superiores e inferiores. As marcas desse processo se fazem presentes na contemporaneidade, haja vista as intensas e diferentes formas de racismo. Dessa forma, consideramos importante problematizar as atuais definições legais de raça, que assumem a norma de "não ver a cor", desconectando a raça da identidade social e da consciência de raça. Nesse, as condições branca e negra são vistas como descrições neutras e apolíticas, sem relação com as condições de dominação e de subordinação. Concordamos com McLaren (2000, p. 263) ao reforçar a necessidade de se trabalhar com o conceito de raça e não substituí-lo por etnia (que objetiva exorcizar o mal do racismo).

\section{Olhares sobre ações políticas internacionais e nacionais para o tratamento de problemáticas relacionadas ao racismo}

Ao propormos reflexões acerca da educação para as relações étnico-raciais, buscando identificar e propor um lugar para o ensino de história que transforme a realidade de crianças e de jovens nos diferentes espaços em que atuamos como professores, não podemos desconsiderar a importância de pensar globalmente, como nos ensina Santos (2002).

Cerezer (2015) empreende um olhar histórico sobre ações políticas internacionais e nacionais que visaram combater o racismo, a discriminação às chamadas minorias (de etnia, de gênero, de sexualidade), a xenofobia e outras formas discriminatórias. $\mathrm{O}$ autor destaca como marco a criação da Organização das Nações Unidas (ONU), em 1948, e a Declaração Universal dos Direitos Humanos (DUDH), ${ }^{1}$ que foi proclamada em Paris, em 10 de dezembro de 1948. A DUDH, segundo o autor, destaca o papel da educação como base comum para que as distintas sociedades possam promover o respeito aos direitos individuais e coletivos e a 
liberdade por meio da adoção de ações de caráter nacional e internacional. Seu artigo $1^{\circ}$ define que todos os seres humanos nascem livres e iguais em dignidade e direitos, são dotados de razão e consciência e devem agir em relação uns aos outros com espírito de fraternidade. No artigo $2^{\circ}$, é determinado que todo ser humano tem capacidade para gozar os direitos e as liberdades estabelecidos na Declaração, sem distinção de raça, cor, sexo, idioma, religião, opinião política, origem nacional ou social, riqueza, nascimento ou qualquer outra condição. A leitura crítica do documento nos permite identificar um discurso hegemônico, pois ele determina a dignidade humana e a igualdade para todos e todas de forma universal, sem levar em conta diferenças culturais e desigualdades sociais. Conforme Santos e Chauí (2013, p. 49), entretanto, esse discurso liberal de dignidade humana tem sido usado para justificar o neocolonialismo, o colonialismo interno, o racismo, a xenofobia, entre outras atitudes. Colocamo-nos, portanto, ao lado dos movimentos sociais que recorrem ao uso democrático desse discurso para reivindicar o direito à diferença e à justiça social para as coletividades excluídas, ou seja, uma concepção contra-hegemônica.

Retomando o histórico das ações internacionais, Cerezer (2015) registra que, em 1957, na cidade de Genebra, na Suíça, foi realizada a Convenção n. 107 da Organização Internacional do Trabalho. $\mathrm{O}$ principal objetivo do encontro consistiu em debater a proteção e a integração das populações indígenas, tribais e semitribais de diversos países. Nessa convenção, a ênfase recaiu na defesa do processo de assimilação das populações indígenas, revelando que havia o reconhecimento das diversas culturas, porém prevalecia uma hierarquia entre as culturas, devendo os "outros" assimilarem a cultura dominante. Em 1989, essa proposta de integração progressiva foi substituída pela proposta de respeito e de preservação das especificidades étnicas e culturais dos povos indígenas (Convenção n. 169 de 1989). ${ }^{2}$

Em seus estudos, Cerezer (2015) destaca algumas medidas, no cenário internacional, tomadas nos anos 1990,
2 O texto completo está disponível em: <https://www. oas.org/dil/port $/ 2001 \% 20$ Declara\%C3\%A7\%C3\%A3o\%20 e $\% 20$ Programa $\% 20$ de $\% 20$ A $\%$ C $3 \%$ A $7 \%$ C $3 \%$ A 3 o $\% 20$ adotado\%20pela\% 20Terceira\%20 Confer $\%$ C $3 \%$ A A n cia $\% 20$ Mundial\%20contra\%20o\%20 Racismo,\%20Discrimina\%C3\% A7\%C3\%A3o\%20Racial,\%20 Xenofobia \%20e\%20Formas\%20 Conexas\%20de\% 20Intoler\%C3\% A2ncia.pdf>. Acesso em 26 out. 2016.

REVISTA GRIFOS - N. 41 - 2016 
que tinham como intuito eliminar com maior rapidez todas as formas de manifestações racistas; delas, ressaltase a Declaração de Viena, em 1993, e o Programa de Ação. Segundo o autor, ainda em 1993, foi criado o cargo de alto comissário da ONU para os direitos humanos, destinado a aproximar os direitos humanos das pessoas vítimas de atos de racismo, discriminação e violação dos direitos humanos. Nos anos 2000, o autor destaca a III Conferência Mundial contra o Racismo, Discriminação Racial, Xenofobia e Intolerância Conexa (ocorrida em 2001), que representou o maior esforço internacional no combate ao racismo, ao preconceito, à xenofobia e a outras formas de discriminação e de intolerância. Após os debates, uma série de ações políticas e medidas concretas foram apontadas como essenciais para o combate e para a erradicação dos males causados pelo racismo e pela intolerância, assim como medidas de prevenção e de educação a serem adotados pelos países membros. Cerezer (2015) ressalta a importância da Declaração e do Programa de Ação de Durban (2001), que declarou a necessidade de os Estados reconhecerem os problemas particularmente graves de preconceito e de intolerância religiosa que muitas pessoas de ascendência africana enfrentam e de pôr em prática políticas e medidas concebidas a fim de prevenir e eliminar toda a discriminação baseada na religião e em convicções, a qual, combinada com outras determinadas formas de discriminação, constitui uma forma de discriminação múltipla. A Declaração solicitou à Comissão de Direitos Humanos considerar a possibilidade de estabelecer um grupo de trabalho ou outro mecanismo das Nações Unidas para estudar os problemas de discriminação racial enfrentados pelas pessoas de ascendência africana que vivem na diáspora africana e para apresentar propostas com vista à eliminação da discriminação racial contra elas. Sobre os povos indígenas, a Declaração e o Programa de Ação de Durban reconheceram que os povos de origem indígena têm sido vítimas históricas de discriminação e que, como esses sujeitos são livres e iguais, não devem sofrer qualquer tipo de discriminação. Em 2008, o documento final 
ressaltou que os povos indígenas têm o direito de manter, controlar, proteger e desenvolver seu patrimônio cultural, seus conhecimentos tradicionais, suas expressões culturais tradicionais e as manifestações de ciências, tecnologias e culturas (Artigo 31).

Os estudos de Cerezer (2015) revelam que o movimento internacional buscou amenizar as consequências do colonialismo e que, em geral, ele reforçou a ideia de superioridade da raça branca em relação aos negros e aos indígenas. $\mathrm{O}$ autor reconhece que a diversidade cultural é um valor estimado para o avanço e para o bem estar da humanidade. Consideramos ser imperativo questionar e desmitificar o discurso dominante sobre o universalismo da dignidade humana, segundo o qual todos os cidadãos são sujeitos de direitos, pois, em nossa perspectiva, os discursos universalizados, que ignoram o contexto social, político e cultural dos diferentes povos e grupos sociais, fortalece projetos e práticas capitalistas ao redor do mundo, contemplando, portanto, uma concepção ocidental e eurocêntrica. Nesse sentido, faz-se necessário a adoção de medidas contrahegemônicas que busquem eliminar toda e qualquer forma de discriminação racial.

$\mathrm{Na}$ continuação deste tópico, registramos algumas ações específicas do Estado brasileiro que tiveram como objetivo combater o racismo. Segundo Paula (2009, p. 178), no Brasil, nos anos 1970, o debate sobre o negro em nossa sociedade ganhou destaque e entraram em cena importantes movimentos de resistência da comunidade negra à superação de estigmas historicamente impostos a essa população. Em um primeiro momento, isso ocorreu por meio de lutas mais gerais contra o racismo e, posteriormente, estendeu-se aos campos da cultura, da educação e da cidadania.

Optamos por registrar, inicialmente, algumas ações afirmativas mais gerais para, em seguida, determo-nos nas Leis $n^{\circ} 10.639$ (BRASIL, 2003) e no 11.645 (BRASIL, 2008), que têm como foco a educação para as relações étnico-raciais. Em 1985, foi promulgada a Lei Federal no 7.437, chamada "Lei 
Caó", que estabelece como crime o tratamento discriminatório, no mercado de trabalho e em outros ambientes, por motivo de raça/cor. Ela classifica o racismo e o impedimento de acesso a serviços diversos por motivo de raça, cor, sexo ou estado civil como crime inafiançável, punível com prisão de até cinco anos e multa.

Em 2003, a Medida Provisória no 111 estabeleceu a criação da Secretaria Especial de Políticas de Promoção da Igualdade Racial (SEPPIR). Essa medida foi transformada na Lei no 10.678 , de 23 de maio de 2003, com o objetivo de se criar um órgão especial de assessoramento direto ao Presidente da República para a criação e a coordenação de políticas públicas afirmativas de promoção da igualdade racial, promovendo e assegurando a proteção dos direitos de sujeitos e grupos raciais e étnicos, com especial ênfase para a população negra.

Em 2010, foi criada a Lei $n^{\circ} 12.288$, instituindo o Estatuto da Igualdade Racial, com o objetivo de assegurar as garantias de igualdade de oportunidades, a defesa dos direitos individuais e coletivos às populações negras e o combate à discriminação e à intolerância étnica. Em 2012, o Governo Federal lançou o Plano Juventude Viva, cujo principal objetivo é constituído por ações que visam o enfrentamento da violência contra a juventude, com especial ênfase para os jovens negros, que são as principais vítimas da violência urbana. Em 2013, o Decreto no 8.136 aprovou o regulamento do Sistema Nacional de Promoção da Igualdade Racial (SINAPIR), que tem o objetivo de atuar na organização e na implementação de políticas destinadas à superação das desigualdades raciais no Brasil, envolvendo as esferas federal, estadual e municipal. Também em 2013, ocorreu, em Brasília, o Fórum Mundial de Direitos Humanos, cujo objetivo foi a promoção de um espaço para o debate público sobre o assunto.

Sobre os povos indígenas, destacamos a criação da Fundação Nacional do Índio (FUNAI) pela Lei no 5.371/67, substituindo o Sistema de Proteção ao Índio (SPI). A FUNAI, desde a sua criação, é o órgão oficial do Estado brasileiro responsável pela proteção dos direitos dos povos indígenas 
espalhados por todo território nacional. Concordamos com a afirmação de Cerezer (2015) de que a atuação da FUNAI, desde sua criação, foi marcada pelo fortalecimento de políticas e ações de tutela, de relações paternalistas, intervencionistas e assistencialistas, da submissão e da dependência dos povos indígenas. Em 1973, foi aprovado o Estatuto dos Povos Indígenas com o objetivo principal de regular a situação jurídica destes, protegendo e fazendo respeitar a organização social e a diversidade cultural, como costumes, línguas, tradições e crenças, além de garantir o direito sobre as terras que eles ocupam. Por meio de uma análise crítica do Estatuto evidenciamos o discurso assimilacionista, que buscava a integração progressiva e harmoniosa das populações indígenas à sociedade e à cultura nacional. Esse discurso foi recorrente, por muito tempo, nas políticas de Estado, que investiam na defesa de projetos de homogeneização cultural.

A Constituição Federal de 1988 é considerada um marco, em termos de reconhecimento de garantias e de direitos dos povos indígenas. Em seu artigo $231^{\circ}$, reconhece-se aos índios sua organização social, seus costumes, suas línguas, suas crenças e suas tradições, além dos direitos originários sobre as terras que tradicionalmente ocupam. Segundo Cerezer (2015), uma das conquistas fundamentais desses povos foi a alteração da política assimilacionista e integracionista pelo reconhecimento dos direitos dos povos indígenas e a preservação das identidades específicas e da diversidade cultural.

Em 2006, o governo federal criou, via decreto, a Comissão Nacional de Política Indigenista (CNPI), com o objetivo de propor diretrizes e prioridades para as políticas destinadas aos povos indígenas. Em 2008, foi promulgada a Lei no 11.696, instituindo o Dia Nacional de Luta dos Povos Indígenas. Em 2012, por meio do Decreto no 7.747, foi instituída a Política Nacional de Gestão Territorial e Ambiental de Terras Indígenas.

Procuramos registrar diferentes circunstâncias em que os movimentos sociais reivindicaram ao Estado a formalização de políticas de combate à discriminação. Nos últimos anos, em 
reposta às persistentes ações reivindicatórias e ao engajamento desses movimentos, foram criadas leis específicas que visam a reparação de direitos e o combate à discriminação. Nesse âmbito, foi instituído, no ensino escolar, como conteúdo disciplinar, a educação para as relações étnico-raciais. Resultado de lutas do movimento negro, no início de 2003, foi sancionada, pelo Presidente da República, a Lei Federal no 10.639, de 9 de janeiro de 2003, que altera a Lei Federal no 9.394, de 20 de dezembro de 1996, a qual determina a inclusão, no currículo oficial da rede de ensino, a obrigatoriedade da temática "História e Cultura Afro-Brasileira". Aquela Lei, conforme assinala Paula (2009), representa um marco da luta por uma educação antirracista no Brasil.

O artigo 26-A da Lei no 10.639 (BRASIL, 2003) salienta a importância do estudo das lutas de africanos e afro-brasileiros e da história e da cultura desses povos, com prioridade não somente nas disciplinas de educação artística, literatura e história, mas em todo o currículo escolar. Devese reconhecer a contribuição da cultura dos africanos e dos afro-descendentes nos aspectos sociais, políticos e econômicos para a formação da identidade brasileira. O artigo 79-B insere o dia 20 de novembro no calendário oficial de todos os estabelecimentos de ensino, públicos e particulares, como o Dia da Consciência Negra, referência evidente à luta dos negros no Quilombo dos Palmares e à morte de um dos seus principais líderes, Zumbi dos Palmares, reconhecido como símbolo do enfrentamento ao regime de escravização e de opressão imposto aos negros africanos pelo Estado colonial português no Brasil. A Lei Federal no 10.639/03 é, em si, um instrumento legal que define a obrigatoriedade do cumprimento daquilo que há muito tempo vinha sendo solicitado por militantes do movimento negro, por educadores e por antirracistas no Brasil: a construção de uma educação antirracista por meio do combate às práticas discriminatórias contra negros e seus descendentes no meio escolar e, de forma mais ampla, no contexto educacional brasileiro. Porém, ante as resistências e as dificuldades encontradas para a implementação dessa lei, tal 
como a necessidade de se estabelecer normas complementares para os sistemas de ensino, o Conselho Nacional de Educação (CNE), aprovou a Resolução no 1, de 17 de março de 2004, que institui as Diretrizes Curriculares Nacionais para o Ensino das Relações Étnico-Raciais e para o Ensino de História e Cultura Afro-Brasileira e Africana (BRASIL, 2004). A partir de então, as escolas da educação básica passaram a ter um documento legal que discute e aprofunda o teor da Lei $\mathrm{n}^{\mathrm{o}} 10.639 / 03$, cuja proposta consiste, fundamentalmente, em orientar a prática pedagógica.

$\mathrm{O}$ advento de um instrumento legal despertou e ampliou o debate acerca da necessidade de outras providências a serem institucionalmente formuladas, a exemplo da lei de cotas, estabelecendo percentual de vagas destinadas à população afrodescendente por ocasião do ingresso no Ensino Superior em universidades públicas. Do mesmo modo, houve também a criação de órgãos governamentais como a Secretaria de Políticas de Promoção da Igualdade Racial (Seppir), em 2003. Posteriormente e no bojo do processo de implementação das chamadas ações afirmativas, foi sancionada a Lei Federal no 11.645, de 10 de março de 2008, que alterou a Lei Federal no 9.394, de 20 de dezembro de 1996 (Lei de Diretrizes e Bases da Educação Nacional), bem como modificou a Lei Federal no 10.639, de 9 de janeiro de 2003, determinando a obrigatoriedade da inclusão, no currículo oficial da rede de ensino, da temática "História e Cultura Afro-brasileira e Indígena".

Ressaltamos que as alterações inseridas na Lei Federal no 9.394/96 e na Lei Federal no $10.639 / 03$ pela Lei Federal $n^{\circ}$ 11.645/08 não invalidam nem revogam nenhuma das duas anteriores, que continuam tendo a sua validade, mas apenas acrescentam, de forma coerente com os pressupostos éticos, teóricos e legais da construção da reeducação das relações étnico-raciais, a inclusão dos povos indígenas.

A inserção da história e cultura afro-brasileira e indígena nos currículos enseja a expectativa de que se conheça os modos de vida, as contribuições e a influência desses 

de ações, nesse sentido, já estavam presentes no artigo $210^{\circ}$ da Constituição de 1988, o qual ressalta a importância em valorizar a presença indígena e reafirmar seus direitos como povos nativos, com intuito de corrigir uma visão deturpada que os homogeneíza como um único grupo devido à justaposição aleatória de traços retirados de diversas etnias. Contudo, fica evidente que o disposto desde tal Constituição ainda não se efetivou na prática.

A implementação das Leis no 10.639/03 e no 11.645/03 representa o reconhecimento, por parte do Estado brasileiro, da existência do racismo e do preconceito racial, iniciando, assim, a implementação de um conjunto de políticas públicas que visam combater as desigualdades entre brancos, negros e indígenas. É possível afirmar que houve um equilíbrio entre o princípio da igualdade e o princípio do reconhecimento da diferença. Concordamos, nesse sentido, com Santos e Chauí (2013, p. 56) ao defender que "temos o direito a ser iguais quando a diferença nos inferioriza e temos o direito a ser diferentes quando a igualdade nos trivializa". Consideramos também que, no processo de ensinar e de aprender história, em uma perspectiva antirracista, que permita o reconhecimento das diferenças e que contribua para a luta contra todas as formas de preconceito e discriminação, o diálogo entre ensino de história e os estudos descoloniais podem potencializar o desempenho dessas ações necessárias.

\section{Possíveis contribuições dos estudos descoloniais para história em situação escolar}

Segundo Grosfoguel (2009, p. 116), em 1998, iniciou o diálogo entre o Grupo Sul-asiático de Estudos Subalternos e o Grupo Latino-americano de Estudos Subalternos, do que resultou na publicação de vários artigos na revista científica Nepantla. Depois desse primeiro encontro, o Grupo Latinoamericano começou a se desagregar. De acordo com Grofoguel, o motivo da desagregação foi o fato de que a maioria dos 
acadêmicos latino-americanistas vivia nos Estados Unidos (EUA) e que, apesar de produzirem um conhecimento alternativo e radical, reproduziam o esquema epistêmico dos Estudos Regionais nos Estados Unidos. À semelhança da imperial epistemologia dos Estudos Regionais, a teoria permaneceu sediada no hemisfério norte, enquanto os sujeitos a estudar encontravam-se no sul. A proposta dos que optaram pelos estudos descoloniais tornou evidente a necessidade de transcender epistemologicamente - ou seja, descolonizar - a epistemologia e os cânones ocidentais. Para o autor,

[...] uma perspectiva epistêmica que parta de lugares étnicos-raciais subalternos pode contribuir em muito para uma teoria crítica descolonial radical, capaz de transcender a forma como os paradigmas da economia política tradicional conceitualizam o capitalismo enquanto sistema global, ou sistema-mundo. A ideia é descolonizar os paradigmas da economia política, bem como a análise do sistema-mundo, e propor uma conceitualização descolonial alternativa do sistemamundo (GROSFOGUEL, 2009, p. 118).

Para efetivar um trabalho com a história, em situação escolar, que proponha um diálogo intercultural abrangendo a educação para as relações étnico-raciais, faz-se necessário compreender os efeitos de uma construção epistemológica pretensamente hegemônica, imposta pela racionalidade europeia. Concordamos com Santos e Meneses (2009), que consideram que as permanências do colonialismo mantiveramse em instâncias para além das formas de exploração e de dominação mais evidentes, nos âmbitos político e econômico da exploração colonial - a colonialidade arraigou-se às mais profundas dimensões constituintes do ser.

O colonialismo tem sido responsável pela disseminação de uma tutela epistemológica hierarquizante de saber-poder que conduziu à supressão de muitas formas de saber próprias de nações e de povos colonizados, relegando uma diversidade de saberes à condição de subalternidade. $\mathrm{Na}$ cultura ocidental, adotou-se uma conduta pautada pela hierarquização de 
formas de conhecimento não europeias, assim como se ignorou suas narrativas, visto que estas supostamente não condiziam com os parâmetros pré-estabelecidos pelas concepções de cunho cientificista de matriz ocidental. Com isso, as populações submetidas ao processo de colonização foram interditadas e suas culturas e modos de ser e viver, desarticulados. Em perspectiva semelhante, Mignolo (2003) assevera que o eurocentrismo funcionou como se não houvesse outras narrativas além das macronarrativas da civilização ocidental ou da modernidade europeia. Esse "epistemicídio" tem sido denunciado por estudiosos vinculados ao pensamento da pós-colonialidade e dos estudos descoloniais como uma das violências mais duradouras efetivadas durante o período colonial.

A partir dessa reflexão consideramos que, ao se ensinar História, na perspectiva da educação para as relações étnico-raciais, é importante o professor ousar a assumir o que pensadores vinculados ao pensamento descolonial denominam "desobediência epistêmica", ao considerarem que a modernidade promoveu uma monocultura das formas de conceber o mundo. Segundo Araújo (2014, p. 126), pesquisas que tiveram como campo empírico as coleções didáticas para o ensino de história aprovadas pelo Programa Nacional do Livro Didático (PNLD) evidenciaram a força de uma organização curricular marcadamente monocultural e eurocêntrica. $\mathrm{Na}$ proposta de um padrão cronológico de organização dos conteúdos, prevalece uma concepção de tempo linear como única possibilidade de organizar o processo histórico, o que revela marcas do eurocentrismo. A professora Circe Bittencourt, há mais de uma década, propunha a superação do eurocentrismo:

O já bastante criticado pressuposto eurocêntrico, que tem presidido a seleção dos conteúdos escolares, pode ser substituído por intermédio de uma reflexão mais aprofundada acerca do próprio conceito de história mundial ou da chamada história da civilização. A história do Brasil precisa necessariamente ser e estar integrada à história mundial para que seja entendida as articulações com a história em escala mais ampla 
e em sua participação nela. A História mundial não pode estar limitada ao conhecimento sobre a história do mundo, que na realidade é a história da Europa. Não se trata de negar a importância e o legado da Europa para a nossa história; trata-se antes, de não omitir outras histórias de nossa herança americanas e africanas (BITTENCOURT, 2004, p. 159).

A autora defendia a integração da história do Brasil com a "história mundial" e reforçava a importância de não se omitir outras histórias de nossa herança, como as americanas e as africanas. Apesar da bandeira de superação do eurocentrismo já ter sido levantada desde o século XX, as propostas curriculares que concordam com isso ainda são bastante tímidas. Estudos evidenciam que os currículos oficiais que fundamentam o ensino de história na educação básica referem-se à diversidade cultural, porém não propõem um diálogo entre culturas, mas sim clamam pelo "respeito" e pela "tolerância”, o que revela a permanência de uma "monocultura". Reforçamos que não basta reconhecer e reivindicar a inclusão da diversidade cultural, pois, como McLaren (2000) alerta, os educadores têm de incorporar e ir além da diversidade. Conforme o autor, o discurso da diversidade e da inclusão é, muitas vezes, predicado com afirmações dissimuladas de assimilação e de consenso que servem como apoio aos modelos democráticos neoliberais de identidade, buscando assimilar as diferenças, tornando-as semelhantes. Nesse sentido, a diferença tende a ser naturalizada, cristalizada e essencializada, mas não problematizada.

Nas palavras de Catherine Walsh (2009), é preciso reconsiderar e refundar, e não simplesmente reformar a educação, uma vez que esta nunca foi pensada para o conjunto da população, para a pluralidade de suas realidades, lógicas, cosmovisões civilizatórias, conhecimentos e sistemas de vida. A proposta da autora permite estabelecer um diálogo com Grosfoguel (2009) ao defender a proposição de descolonizar o conhecimento, o que exige levar a sério as perspectivas/ cosmologias/visões de pensadores críticos do Sul Global, que 
pensam com e a partir de corpos e de lugares étnico-raciais/ sexuais subalternizados; assim, é possível identificar outras histórias possíveis. $\mathrm{O}$ saber histórico escolar pode constituirse como lugar de diálogos interculturais com essas outras histórias.

Faz-se necessário romper com as amarras do eurocentrismo que produziram concepções distorcidas e estereotipadas sobre a história e a cultura dos africanos, dos afro-brasileiros e dos indígenas no Brasil. O ensino de história, ao estabelecer diálogos com os estudos descoloniais, pode mobilizar os sujeitos (estudantes e professores), além de seus saberes e ações, para a construção de um novo sentido para a história. Compete ao professor dessa disciplina a tarefa de fazer com que os estudantes compreendam o processo histórico de construção das diferenças em relação ao "outro", sua história, sua cultura e sua identidade. A relação professorestudante implica pensar o conhecimento, sobretudo o conhecimento escolar, como algo em permanente estado de reconstrução, não mais como um dado, um fato cristalizado ou uma verdade absoluta e imutável.

Concordamos com Gomes (2013) quando este afirma que a escola é uma das instituições sociais responsáveis pela construção de representações positivas dos afro-brasileiros e por uma educação que respeite a diferença, atuando como parte fundamental na construção de uma educação antirracista. Nesse processo, o ensino de história pode ser protagonista ao problematizar os processos de seleção cultural e de constituição desses saberes. Historicamente, ao se falar de África, reportavase mais ao escravismo e ao processo de escravidão. Na trajetória escolar, aprendemos a ver a África e os africanos escravizados mediante as representações dos pintores Debret e Rugendas, que representavam crianças negras brincando aos pés dos senhores, africanos escravizados recebendo castigos, instrumentos de tortura, o navio negreiro, algumas danças típicas, entre outros elementos; essas representações dos artistas ajudaram a forjar o imaginário social sobre a nossa ancestralidade negra e africana (GOMES, 2013, p. 75). 
As imagens veiculadas sobre a África privilegiavam a representação de um continente dividido e reduzido a guerras "tribais", fome, calamidades naturais, doenças endêmicas, etc. Elas raramente mostram os vestígios de palácios reais ou de impérios, imagens de reis e muito menos o retrato de cidades modernas africanas construídas pelos próprios excolonizadores. De acordo com Gomes (2013, p. 76), a África e negros brasileiros são vistos de forma cristalizada, estereotipada e, muitas vezes, animalizada. Essas imagens vêm à mente de formas isoladas, desconexas, desarticuladas de uma discussão mais ampla sobre o contexto histórico, político e cultural da época. Ao fazerem parte da vivência curricular na escola, imagens extrapolaram o aprendizado dos conteúdos propriamente ditos e formam subjetividades, produzem discursos sobre o outro e sobre as diferenças; nesse sentido, dificilmente as imagens de que tratamos possibilitariam a construção de subjetividades mais abertas ao trato das diferenças.

Ao propormos o estudo da África e das culturas afrobrasileira e africana na perspectiva mais ampla da educação das relações étnico-raciais, é imperativo considerar o estudo da África do passado e do presente em uma perspectiva histórica, geográfica, cultural e política. Assim, é possível problematizar o imaginário racista brasileiro fundamentado na inferiorização da nossa ascendência africana, limitando os africanos escravizados à condição de escravos. Assim, a proposta de um diálogo intercultural,

Não se trata de construir uma históriarevanche, que relançaria a história colonialista como um bumerangue contra seus autores, mas de mudar a perspectiva e ressuscitar imagens "esquecidas" ou perdidas. Tornase necessário retornar à ciência, a fim de que seja possível criar em todos uma consciência autêntica. É preciso reconstruir o cenário verdadeiro. É tempo de modificar o discurso (KI-ZERBO, 2010, p. XXXII).

A afirmação de Ki-Zerbo nos instiga a refletir sobre os problemas de uma história única. É importante que o professor 
de história mobilize os estudantes a um diálogo horizontal entre as diferentes culturas que marcam o espaço escolar. Lembramos que a escola é uma arena de tensões e de conflitos, na qual temos saberes e práticas matizadas por subjetividades, intencionalidades e sensibilidades. Ela é, portanto, é um espaço prenhe de significados, memórias e histórias, que transcende sua materialidade física para constituir-se em um lugar de sujeitos e interesses plurais.

Segundo Martins (2009), tantos os livros didáticos como a historiografia tradicional reproduz, de modo simplificador e estereotipado, a imagem das populações autóctones do território definido brasileiro. Ressalta-se que a perspectiva que ganhou grande evidência, nesses materiais, foi a "Visão dos Vencidos"; as obras que se filiam a essa corrente, que falam de testemunhos dos "sobreviventes", abatidos por um "profundo trauma", bem como dos efeitos da "destruição da cultura indígena", tiveram forte aceitação no âmbito escolar. De acordo com a autora, embora simpática aos índios, essa visão do passado perpetua, inadvertidamente, uma compreensão que acaba por se mostrar muito pouco favorável a eles, pois a visão que prevalece é de que as sociedades indígenas estão destinadas a desaparecer. Chamamos a atenção para o fato de que os povos que eram tidos como fadados à extinção hoje estão vivos, atuantes, presentes, organizados e cobrando do poder público a implementação de seus direitos.

Ao retomar o diálogo com os estudos descoloniais, ressaltamos o questionamento de Grosfoguel (2009, p. 122): "Como seria o sistema-mundo se deslocássemos o lócus da enunciação, transferindo-o do homem europeu para as mulheres indígenas das Américas, como por exemplo, Rigoberta Menchu da Guatemla ou Domitilia da Bolívia?”. Ao deslocar o lugar a partir do qual estes paradigmas são pensados, a primeira conclusão é que aquilo que chegou às Américas, nos finais do século XVI, não foi apenas um sistema econômico de capital e de trabalho, mas um "pacote" mais complexo e enredado, isto é, uma estrutura de poder mais ampla e mais vasta que uma redutora perspectiva econômica do sistema- 
mundo. Às Américas chegou, genericamente, o homem heterossexual, branco, patriarcal, cristão, militar, capitalista e europeu com suas várias hierarquias globais enredadas e coexistentes no espaço e no tempo (GROSFOGUEL, 2009, p. 123).

Ao ensinar história, colocando-se ao lado da educação para as relações étnico-raciais, é preciso que o professor compreenda que essa postura política precisa prevalecer ao longo do cotidiano escolar. Assim, é possível contribuir para uma educação antirracista e, consequentemente, para uma transformação social, uma vez que, reiteramos, a tarefa do professor é produzir inteligibilidade recíproca entre experiências possíveis e disponíveis.

\section{Considerações finais}

As reflexões registradas neste texto foram mobilizadas pela seguinte questão: como o ensino de história pode contribuir para a educação das relações étnico-raciais? Ressaltamos que o saber histórico escolar tem uma especificidade epistemológica, não é uma simples adaptação didática do conhecimento científico, tampouco uma versão simplista, equivocada ou desatualizada. O ensino de História, em nossa concepção, a partir do diálogo com os estudos descoloniais, pode se configurar como lugar de debate, de reflexões e de diálogos interculturais ao recorrer à educação das relações étnico-raciais.

Acreditamos que o desafio que é a construção de um projeto educacional que tenha como foco a construção de relações étnico-raciais positivas da perspectiva de combate às práticas racistas, discriminatórias e excludentes no meio educacional e escolar tem avançado significativamente em comparação ao que vivíamos há algumas décadas. Ao considerarmos o saber escolar na sua dimensão cultural, é possível reconhecê-lo como espaço de produção de significados. É imperativo, portanto, estabelecer diálogos horizontais entre saberes e sujeitos. 
Ressaltamos que a interpretação equivocada das Leis $n^{\circ} 10.639 / 03$ e $n^{\circ} 11.645 / 08$ pode resultar, na escola, em ações desconexas e estanques que tendem a folclorizar a discussão sobre a questão racial. Julgamos que trabalhos pontuais nas chamadas datas comemorativas ou palestras, apresentações de capoeira, desfile de beleza negra, etc., sem se discutir e contextualizar de forma séria o que se realiza, pode ter poucos resultados. $\mathrm{O}$ alerta aqui proposto refere-se ao cuidado com a forma como essas iniciativas pedagógicas podem ser realizadas e a necessidade de articulá-las com estudos e reflexões mais profundas, levando-se em consideração também os alunos e alunas dos diversos níveis de ensino em seus diferentes ciclos de vida. Mais do que atividades pedagógicas novas, a discussão sobre a África, o negro e o índio, no contexto brasileiro, devem promover o debate, a discussão, a reflexão e a mudança de postura.

No processo de caminhar rumo a um projeto de educação de fato inclusiva, republicana, libertadora e plural, temos ainda muitos desafios. Devemos considerar que é na escola que recebemos informações que ajudarão a compor nossas formas de conhecer e lidar com as diferenças culturais e assim construir a imagem que fazemos do "outro". Dessa forma, construir relações étnico-raciais positivas, fundadas no respeito às diferenças e no reconhecimento da alteridade, deve ser pauta fundamental nas aulas de história. Ao promover diálogos horizontais entre as diferenças, o dessa disciplina poderá se aproximar de um lema dos zapatistas: "Lutar por um mundo onde outros mundos sejam possíveis" (GROSFOGUEL, 2009, p. 127 ).

\section{Referências}

ARAÚJO, Cinthia. O trabalho da tradução no saber histórico escolar: diálogos interculturais possíveis. In: MOREIRA, Antonio Flávio, CANDAU, Vera Maria (Org.). Currículos, disciplinas escolares e culturas. Petrópolis, RJ: Vozes, 2014.

BITTENCOURT, Circe Maria Fernandes. Ensino de História: fundamentos e métodos. São Paulo: Cortez, 2004. 
BRASIL. Lei no 10.639, de 9 de janeiro de 2003. Altera a Lei no 9.394, de 20 de dezembro de 1996, que estabelece as diretrizes e bases da educação nacional, para incluir no currículo oficial da Rede de Ensino a obrigatoriedade da temática "História e Cultura Afro-Brasileira", e dá outras providências. Brasília, 2003. Disponível em: <http://www. leidireto.com.br/lei-11645.html>. Acesso em: 20 jul. 2016.

BRASIL. Lei $\mathrm{n}^{\circ} 11.645$, de 10 de março de 2008. Altera a Lei $\mathrm{n}^{\mathrm{o}}$ 9.394, de 20 de dezembro de 1996, modificada pela Lei no 10.639 , de 9 de janeiro de 2003, que estabelece as diretrizes e bases da educação nacional, para incluir no currículo oficial da rede de ensino a obrigatoriedade da temática "História e Cultura Afro-Brasileira e Indígena”. Brasília, 2008. Disponível em:<http://www.leidireto. com.br/lei-11645.html>. Acesso em: 20 jul. 2016.

. Conselho Nacional de Educação. Conselho Pleno. Parecer CNE/CP no 3/2004: Diretrizes Curriculares para a Educação das Relações Étnicos-Raciais e para o Ensino de História e Cultura Afro-Brasileira e Africana. Brasília, 2004.

CEREZER, Osvaldo Mariotto. Diretrizes Curriculares para o Ensino de História e Cultura Afro-Brasileira e Indígena: implementação e impactos na formação, saberes e práticas de professores de História iniciantes (Mato Grosso, Brasil). 2015. 327 f. Tese (Doutorado em Educação)-Universidade Federal de Uberlândia, Uberlândia, 2015.

GOMES, Nilma Lino. A questão racial na escola: desafios colocados pela implementação da Lei 10.639/03. In: MOREIRA, Antonio Flávio; CANDAU, Vera Maria (Org.).Multiculturalismo: diferenças culturais e práticas pedagógicas. Petrópolis, RJ: Vozes, 2013.

GROSFOGUEL, Ramón.Para descolonizar os estudos de economia política e os estudos pós-coloniais: transmodernidade, pensamento de fronteira e colonialidade global. In: SANTOS, Boaventura Sousa; MENESES, Maria Paula (Org.). Epistemologias do Sul. Coimbra: Almedina, 2009.

KI-ZERBO, Joseph. História Geral da África: I: metodologia e pré-história da África. Brasília: UNESCO, 2010.

MARTINS, Maria Cristina Bohn. As sociedades indígenas, a história e a escola. Antíteses, Londrina, v. 2, n. 3, p. 153-167, jan./ jun. 2009.

MCLAREN, Peter. Multiculturalismo Revolucionário: pedagogia do dissenso para o novo milênio. Porto Alegre: Artes Médicas do Sul, 2000.

MIGNOLO, Walter. Os esplendores e as misérias da 'ciência': colonialidade, geopolítica do conhecimento e pluri-versalidade epistêmica. In: SANTOS, Boaventura de Sousa (Org.). 
Conhecimento Prudente para uma vida decente: 'Um discurso sobre as ciências'. Porto: Afrontamento, 2003.

PAULA, Benjamin Xavier de. O ensino de história e cultura da África e afro-Brasileira: da experiência e reflexão. In: GUIMARÃES, Selva (Org.). Ensinar e aprender História: formação saberes e práticas educativas. Campinas, SP: Editora Alínea, 2009.

SANTOS, Boaventura de Sousa. A Globalização e as Ciências Socais. 2. ed. São Paulo: Cortez, 2002.

SANTOS, Boaventura de Sousa; MENESES, Maria Paula (Org.). Epistemologias do sul. São Paulo: Cortez, 2009.

SANTOS, Boaventura de Sousa; CHAUÍ, Marilena. Direitos Humanos, democracia e desenvolvimento. São Paulo: Cortez, 2013.

WALSH, Catherine. Interculturalidade, Estado, Sociedade: Luchas (de)coloniales de nuestra época. Quito: Universidad Andina Simon Bolivar; Abya Yala, 2009.

Submetido em: 18/11/2016

Aprovado em: 14/12/2016

\title{
HISTORY OF EDUCATION AND EDUCATION FOR ETHNIC-RACIAL RELATIONS: DIALOGUE WITH STUDIES DECOLONIAL
}

\begin{abstract}
This article following question: how history teaching can contribute to the education of ethnicracial relations? It aims to propose some reflections on the place of history teaching in the education of ethnic-racial relations from dialogue with decolonial studies. The methodology consisted of bibliographic research on history teaching, education for ethnic-racial and decolonial studies relationships. It presents a study on the concept of race; records a look at the history of national and international political action to address issues related to racism to understand the importance of education for ethnic-racial relations; It presents a proposal to effect a school history from the contributions of descolonais studies. It was concluded that it is in school we receive information that will help make our ways of knowing and dealing with cultural differences and thus build the image we have of the "other." Thus, build ethnic-racial relations positive, based on respect for differences and recognition of otherness, must be fundamental agenda in history classes.
\end{abstract}

Keywords: Education for ethnic-racial relations. History teaching. Decolonial studies. 